\title{
Desejo feminino e subjetividade em narrativas de língua inglesa: em(cena)ação ficional de amores
}

Maria Conceição Monteiro

Recebido em 15/07/2011

\section{Resumo}

Focado no romance produzido no âmbito das literaturas de língua inglesa, o texto parte de um recorte temático que colocará em relevo as figurações narrativas da vida conjugal. Trata-se pois de explorar o casamento num sentido duplo: o "casamento" (perfeito) entre a forma do romance e a encenação ficcional de amores; e o casamento enquanto tema de romances. Privilegiando-se o subtema do adultério de personagens femininas, a análise incide em momentos especialmente intensos das tramas romanescas ("cenas", nos quais o desejo eclode em forma textual até certo ponto destacável do conjunto narrativo em que se insere). Como ilustração da teoria, propõe-se uma leitura do romance The End of the Affair (1951), de Graham Greene.

Palavras-chave: adultério; corpo; desejo erótico; feminismo; subjetividade 


\section{Bastidores}

Segundo certa crítica, enquanto na segunda metade do século XIX o romance sobre o adultério da esposa florescia na Europa continental, na Inglaterra o tema permanecia um tabu. Não estava, contudo, ausente do mundo literário vitoriano, antes mesmo de Elizabeth Braddon, Meredith, Hardy e James. Chegara inclusive a ser um tema-chave em várias narrativas inglesas desde o final da Restauração até fins do século XVIII, cabendo lembrar que Love-Letters Between a Nobleman and his Sister (1684-1687), de Aphra Behn, por muitos considerado o primeiro romance inglês, é um romance de adultério.

Assim, já no final do século XVIII diversos romances de adultério foram escritos por mulheres, gerando muita controvérsia. Talvez o motivo para a redução do seu número no século subsequente tenha sido a transformação de conduta e mentalidade operada no período. Para o historiador Lawrence Stone (1977), apesar de as manifestações e causas dessas mudanças variarem entre as classes, nesse período ocorreu uma grande alteração nas atitudes e comportamentos sexuais. Entre dois períodos de repressão moral - sob o influxo do puritanismo no começo do século XVII e sob a liderança metodista e evangélica no início do século XIX -, por mais de um século os ingleses de alta e baixa classes assumiram uma atitude tolerante em relação ao comportamento sexual. É verdade que a posição de Stone tem sido questionada, mas não se costuma pôr em dúvida que o período que se estende da Restauração até as primeiras décadas do século XVIII foi de tolerância sexual fora do comum, tanto na linguagem quanto na ação, pelo menos nos meios aristocráticos e na alta burguesia.

Desse modo, a emergência de tal ficção na Inglaterra deveuse em boa medida a uma cultura de condescendência em relação à vida sexual nas altas classes, especialmente na Corte, de que é indício a difusão do pensamento libertino e o gosto por certo tipo de narrativa já comum na França, que girava não apenas em torno do amor, mas do escândalo sexual. Dessa forma, a ética do amor nos romances do período pode ser explicada, em parte, como no caso do romance de Behn, como resposta ao sistema de casamento arranjado, prática que se estende até o século XIX, nos meios aristocráticos.

Entre os motivos alegados para a ausência do romance de adultério na Inglaterra oitocentista figuram a censura oficial e a extra-oficial, bem como a ideologia e a prática do casamento por amor. Outro motivo é que, depois do Ato da Causa Matrimonial de 1857, o tópico do adultério teria migrado para o jornalismo dedicado a cobrir os julgamentos ocorridos no âmbito da Corte Britânica de Divórcio. Outro motivo seria ainda o fato de que os escritores se achavam tanto intimidados por reações políticas 
quanto limitados por uma moralidade evangélica, assim como pela luta que tiveram de travar para legitimar o romance como forma literária respeitável. Por isso, certamente, preferiam não aventurar-se por um tema que lhes ameaçaria a reputação. Todas essas razões devem ter contribuído para explicar o motivo de o tema não ter sido tão difundido na Inglaterra como o fora na França, mas o fato é que todos esses motivos não foram suficientes para eliminá-lo da produção ficcional do período.

Observa-se que o próprio adultério é de tal modo carregado de consequências morais e ideológicas que qualquer tipo de consenso, até mesmo sobre a representação literária, nunca é muito viável. Acrescente-se a isso que não há concordância sobre o que conta como adultério na ficção, ou mesmo o que é um romance de adultério. Tonny Tanner (1979), ao analisar La Nouvelle Heloïse, de Rousseau, e Die Walverwandtschaften, de Goethe, afirma que nessas obras o ato físico do adultério nunca na verdade ocorre. Entretanto, Bill Overton (2002) ressalta que por romance de adultério entende-se qualquer romance em que uma ou mais ligações adúlteras são não apenas centrais, mas revelam perfeita identificação com a ação, o tema e as estruturas propostas. Somente nesse tipo de romance - quase sempre figurando o adultério de esposa - o tema condicionará toda a estrutura narrativa. Convém notar que também há romances onde o adultério ocorre sem se constituir no foco principal, como é o caso de Vanity Fair, de Thackeray, entre outros tantos. Existem ainda romances onde o adultério acontece apenas no plano do desejo, como, por exemplo, em Wuthering Heights, de Emily Brontë.

Vale ressaltar, contudo, que a simples circunstância de o desejo adúltero se manifestar, de fato ou apenas na fantasia, sinaliza para a mesma problemática, ou seja, a insatisfação da mulher no espaço matrimonial.

A presente análise incidirá em momentos especialmente intensos da trama romanesca, nos quais o desejo eclode em forma textual até certo ponto destacável do conjunto narrativo em que se insere, forma a que denomino "cena". Assim, o ensaio consistirá no destaque de "cenas" do romance The End of the Affair, de Graham Greene, visando a verificar a adequação recíproca entre dispositivos formais e perspectivas de tratamento ficcional do tema em causa.

\section{Abrem-se as cortinas}

Apesar de parecer datado, devido aos avanços econômicos e políticos na situação da mulher, o senso comum tende a concordar com Simone de Beauvoir, quando ela afirma que o casamento é o destino tradicionalmente oferecido à mulher pela sociedade. Assim, o casamento moderno só poderá ser compreendido à luz de um passado que tende a se perpetuar. 
No século XIX, a mulher ainda era subordinada ao homem. Ele era a cabeça do empreendimento econômico do casal. Até nos nossos dias, a mulher, com algumas exceções, ainda adota o nome do homem, tornando-se a sua metade. Nas palavras de Beauvoir, a mulher estava condenada à continuação da espécie e aos cuidados da casa - ou seja, à imanência. No entanto, o fato é que a existência humana envolve transcendência e imanência ao mesmo tempo, e o casamento para o homem permite uma síntese feliz das duas dimensões (cf. BEAUVOIR, 1997, p. 449).

À vista disso, em uma sociedade patriarcal, em que os interesses e prazeres masculinos têm prioridade, o prazer sexual da mulher é limitado a uma forma específica e não individualizada. Entretanto, ainda que ambos os sexos sofram as consequências de uma sexualidade institucionalizada, à mulher cabe sempre a menor parte do latifúndio do prazer. Em outros termos, ao cumprir a tarefa de agente reprodutor, o homem obtém, de alguma forma, o prazer sexual; na mulher, ao contrário, a função reprodutiva é usualmente dissociada do prazer erótico. Nesse contexto, o que o otimismo burguês tem a oferecer à mulher não é a satisfação erótica, mas uma felicidade calcada em um equilíbrio tranquilo, uma vida de imanência e repetição, sem paixão. Ainda assim, mesmo com dificuldade de libertar-se dessas influências e dos princípios que passa a vida repetindo, a mulher é capaz de preservar a sua própria visão peculiar das coisas. Essa resistência faz com que ela se subtraia ao domínio do outro.

Vale lembrar, contudo, que desde o nascimento do Cristianismo a figura da mulher tornara-se espiritualizada. Todos os atributos femininos desejados pelo homem deixam de ser qualidades tangíveis, passando a mulher a ser sua alma, a verdade do mundo. A mulher torna-se a alma do lar, da família.

Segundo Beauvoir, a mulher existe além dessa invenção. Daí não ser apenas a encarnação do sonho masculino, mas também a sua frustração. Não existe imagem figurativa da mulher que não suscite o seu oposto: ela é vida e morte, natureza e artifício, luz e noite. Sob qualquer aspecto que a mulher seja considerada, haverá sempre esse movimento alternado, pois o não essencial retorna necessariamente ao essencial (cf. BEAUVOIR, 1997, p. 218).

Contudo, para que a mulher se tornasse submissa ao homem, através de cerimônias e contratos, era necessário elevá-la à posição de pessoa humana, dando-lhe liberdade. Mas a liberdade, todavia, sendo aquilo que escapa à sujeição, pode prestar-se a uso negativo, daí decorrendo sua rejeição pela mulher. Desse modo, a mulher liberta-se quando se torna cativa; ela assim renuncia à liberdade para adquirir poder como objeto natural. Por isso, está destinada à infidelidade, forma concreta de recuperação da liberdade. Consequentemente, só através do 
adultério a mulher prova que não é propriedade de ninguém, conquistando assim a posição de sujeito. Se, por outro lado, a mulher rompe com as regras da sociedade, ela perde as forças incontroláveis, restando-lhe, assim, o medo, que está sempre ligado à conduta licenciosa feminina (cf. BEAUVOIR, 1997, p. 222).

Entretanto, assim como o Cristianismo, ao criar as ideias de redenção e salvação, deu à palavra salvação um significado completo, também o fez ao colocá-la em contraste com a mulher santificada. Observa-se, assim, o Bem e o Mal como opostos: a mãe devotada e a amante pérfida. Por entre esses polos fixos pode-se discernir uma multiplicidade de figuras ambíguas, como a angélica, a diabólica, a vítima, a pecadora, etc.

Por ser considerada o Outro, a mulher é outro dela mesma, outro do que é dela se espera. E ao ser tudo, ela nunca é aquilo que deveria ser. A mulher fornece, dessa forma, uma variedade de comportamentos e sentimentos que estimula os estereótipos construídos em relação a ela pela sociedade.

Tal problema emerge devido ao fato de que a questão do gênero sempre remete a uma compreensão idealizada que o sujeito constrói acerca de si mesmo. Se considerarmos a posição de Beauvoir sobre o assunto, observar-se-á que a questão sobre o que é uma mulher nunca poderá limitar-se a uma única resposta. Assim, não há razão para acreditar que as palavras mulher ou homem apresentem sempre em seus respectivos significados algo de inerentemente metafísico ou essencialista.

Daí a importância, segundo Toril Moi, de se renunciar à tentação de falar sempre sobre sexo e gênero, e, em contrapartida, a necessidade de optarmos por termos como corpo e subjetividade. Para Beauvoir (1997), a relação entre o corpo e a subjetividade não é nem necessária nem arbitrária, mas contingente. Por isso, a ambiguidade do corpo não está sujeita às leis naturais de causa e efeito, e tampouco constitui simplesmente um efeito da consciência, do poder, da ideologia ou dos discursos regulatórios. Para Moi, considerar que a subjetividade está numa relação contingente com o meu corpo é reconhecer que o meu corpo influenciará tanto o que a sociedade faz de mim quanto os tipos de escolhas que farei em resposta à imagem que o outro faz de mim. Vale ressaltar, também, que nenhuma forma de subjetividade é sempre consequência necessária de se ter um corpo específico (cf. MOI, 1999, p. 59-112).

Quando Beauvoir afirma "Eu sou uma mulher", não quer dizer que ela é uma criatura que se conforma às normas de gênero prescritas pela sociedade. Para ela, o verbo significa existência, e a existência é sempre um processo que implica um tornar-se. Assim, é importante pensar o corpo e a subjetividade como formas de nos libertar de um quadro ideológico determinante, buscando-se alternativas sempre mais e mais libertadoras na maneira de pensar. 
Segundo Moi, na trilha aberta por Beauvoir, o corpo como situação constitui uma alternativa poderosa e sofisticada para as teorias de sexo e gênero. Ver o corpo como uma situação é reconhecer que o corpo da mulher está ligado à forma que usa a sua liberdade (cf. MOI, 1999, p. 65). Assim, a subjetividade não é nem uma coisa, nem o mundo emocional interior; mas é, ao contrário, a forma que somos no mundo.

\section{The End of the Affair: amor e morte en(cena)}

Ilustremos agora o background teórico apresentado mediante a leitura de um importante romance publicado em meados do século passado.

The End of the Affair (1951), de Graham Greene (1904-1991), é a história de amor entre Maurice Bendrix e Sarah, que floresce na atribulada Londres do tempo da Segunda Guerra Mundial, chegando ao fim quando Sarah, de repente e sem explicação, termina o caso.

Maurice, o narrador, tem duas grandes paixões. A primeira, ligada ao seu lado de escritor, concerne ao misterioso ato de criação; a segunda, a uma arte ainda mais misteriosa: a da relação amorosa.

A narrativa se abre com o narrador desenvolvendo uma reflexão sobre o ódio:

Se o ódio não é um termo amplo para se usar em relação a qualquer ser humano, eu odiava Henry - odiava a sua esposa Sarah também. E ele, acredito, logo depois dos eventos daquela noite, passou a me odiar: como também em alguns momentos deve ter odiado sua esposa [...]. Então este é um registro de ódio muito mais que de amor (GREENE, 2001, p. 1 , grifo meu).

Depois da primeira separação dos amantes, Henry marca um encontro com Maurice em que confessa desconfiar de Sarah. Quando conversam sobre o assunto, já na casa de Henry, chega Sarah. É importante observar nessa cena a diferença na atitude dos dois homens à chegada de Sarah. Henry vai até a porta para recebê-la, e "[...] automaticamente o seu rosto se cobre em linhas de generosidade e afeição" (GREENE, 2001, p. 11). Maurice, por sua vez, quer que o leitor perceba Sarah no momento em que ela para no corredor ao pé da escada e se vira para eles: "Tudo que posso passar [ao leitor] é uma figura indeterminada, virando-se [...], dizendo, 'Sim, Henry?', e depois 'Tu'. Ela sempre me tratou por 'tu'. [...] imaginava como um tolo, por alguns minutos a cada momento, que havia apenas um 'tu' no mundo, e que era eu' (2001, p. 11).

A cena do primeiro encontro concentra-se na percepção física do objeto de desejo: "Tudo que percebi sobre ela na primeira vez foi a sua beleza e alegria, e a forma como tocava as pessoas 
com as mãos, como se as amasse" (GREENE, 2001, p. 18). Para completar a cena, ele descreve poeticamente o espaço:

O sol pálido caía sobre a praça e a grama. Na distância as casas eram como casas numa gravura vitoriana, pequenas e desenhadas com precisão e calma: somente uma criança chorava à distância. A igreja setecentista erguia-se como um brinquedo numa ilha de relva - o brinquedo poderia ficar de fora na escuridão, no tempo seco e inquebrável. Era a hora em que se fazem confidências a um estranho (GREENE, 2001, p. 19).

Era o momento em que conversava com Henry pela primeira vez, e este lhe falava de Sarah.

Depois do último encontro entre Maurice e Henry, Sarah propõe a Maurice que eles se encontrem mais uma vez. Ela chega ao local combinado pedindo desculpas pelo atraso, pois viera de ônibus. "O metrô seria mais rápido", diz Maurice; ao que ela responde: "Eu sei, mas não queria chegar rápido" (GREENE, 2001, p. 21).

Enquanto essa rápida conversa tem lugar, Maurice reporta-se ao passado. Quando estavam apaixonados, ele tentava arrancar dela mais que a verdade - que o caso nunca acabaria e que um dia se casariam.

Eu não teria acreditado nela, mas teria gostado de ouvir as palavras na sua língua, talvez apenas para ter a satisfação de rejeitá-las. Mas ela nunca jogou o jogo do faz-de-conta, e de repente, inesperadamente, despedaçaria as minhas cautelas, com uma frase de tamanha doçura e ressonâncias... Lembro-me que, certa vez, eu triste com sua tranquila pressuposição de que um dia a nossa relação acabaria, a ouvi dizer com incrível alegria: 'Eu nunca, nunca amei um homem como te amo, e nunca amarei novamente' (GREENE, 2001, p. 21).

E como falta a Maurice o conhecimento profundo de Sarah, ele logo pensa: "[...] bem, ela não sabia, pensei, mas ela também jogava o jogo do faz-de-conta" (GREENE, 2001, p. 21).

Nesse encontro, o desejo passado recrudesce, e no final Maurice não consegue soltar-lhe as mãos, mas é interrompido pela tosse de Sarah. Como as heroínas adúlteras do século XIX, Sarah tosse, o que soa como um mau presságio.

Na trama do romance, uma circunstância que aparece clara, dada a recorrência de situações narrativas que a configuram, é a incapacidade de Maurice para amar livremente. Ele é refém de seu próprio medo: o medo de perder Sarah, que o leva a antecipar a dor, a perda, a querer que o amor acabe:

O tempo todo sabia que forçava o passo. Estava empurrando, empurrando a única coisa que amava na vida. [...]. Mas o amor tinha que morrer, queria que morresse rápido. Era como se o nosso amor fosse uma criaturinha presa numa armadilha e sangrando até morrer: tinha que fechar os olhos e torcer o seu pescoço (GREENE, 2001, p. 25). 
Observa-se que o título do romance sinaliza o maior medo de Maurice: o fim do caso. E é nesse momento que Sarah desaparece de sua vida. Dois anos se tinham passado, desde que se encontraram no corredor, ela se dirigindo a ele por " $t u$ ".

Maurice e Heathcliff são personagens que tomam a cena, pela complexidade das suas angústias, pela força dos impulsos conflituosos, pela obscura capacidade de amar e, por último, pela incapacidade de libertarem-se das relações amorosas. Talvez pelo fato de suas amantes, Sarah e Catherine respectivamente, serem partes deles próprios, os seus duplos, e, como tais, suas desconhecidas.

Maurice fala, reiteradamente, sobre o amor e o ódio, o fim e o começo, sem possibilidade de alívio ou descanso. Sarah, por sua vez, é focalizada na visão de Maurice através do diário que chega às mãos dele. Ele então "lề" os sentimentos dela como nunca fora capaz de vê-la, de conhecê-la. Começa, por sinal, a ler o diário pelo fim.

Dois anos depois que principiara a escrever o diário, Sarah afirma convicta: "Quero Maurice. Quero o amor humano simples e corrupto. Meu Deus, sabes que quero querer a Tua dor, mas não a quero agora. Tira-a de mim por um tempo e me dê em um outro momento" (GREENE, 2001, p. 71).

A partir desse ponto, Maurice decide recomeçar a leitura desde o início, 1944, ano em que Sarah o deixara. Tem acesso, só então, à intimidade interior de Sarah:

\begin{abstract}
Sei que teme o deserto que o envolverá se o nosso amor acabar, mas ele não percebe que sinto exatamente o mesmo [...]. Ele sente ciúmes do passado, do presente e do futuro. O seu amor é como um cinto de castidade medieval: somente quando ele está comigo, em mim, sente-se seguro. [...] Sempre quis ser querida e admirada. [...] Deus te ama, é o que dizem nas igrejas. As pessoas que acreditam nisso não precisam de admiração. [...] Mas não posso inventar uma crença. [...] Se amasse Deus, não precisaria acreditar no seu amor por mim, então (GREENE, 2001, p. 72-73).
\end{abstract}

Entretanto, a pergunta central para Sarah e para o leitor é: Por que persistir em manter a promessa feita num momento de medo para um Deus em quem não se acredita? Greene levanta a questão a todo momento, cercando-a por ângulos diversos: algumas vezes nas conversas entre Sarah e o ateu Smythee, outras através da reflexão atormentada de Sarah; e, ao final, ela confessa o seu momento de revelação: “Quando surgiste retirar na porta com o rosto coberto de sangue, eu tive certeza. De uma vez por todas" (GREENE, 2001 p. 75). É aí, então, que Maurice lê sobre o que acontecera na noite do bombardeio, quando os dois estavam juntos na casa dele: "Deixe-o viver e eu acreditarei. Dêlhe uma chance. Então eu disse, eu amo e farei qualquer coisa se o fizeres viver. [...] então ele surgiu na porta, e estava vivo, 
e pensei, agora a agonia de ficar sem ele começa, e desejei que estivesse morto novamente, sob a porta" (2001, p. 76).

Sarah recorre a tudo para poder quebrar a promessa e voltar para Maurice. Precisa acreditar que pode quebrá-la. Assim, num dia quente e chuvoso, entra na igreja escura e, depois de sentar-se e olhar à volta, percebe que estava num templo católico. Odiava as estátuas, o crucifixo, toda aquela ênfase no corpo humano:

Pensei que pudesse acreditar em um tipo de deus que tivesse uma relação com a gente, algo vago, amorfo, cósmico, para quem prometesse algo e que me desse alguma coisa em retorno. [...] lembrei que acreditavam na ressurreição do corpo, o corpo que queria destruído para sempre. [...] Se pudesse inventar uma doutrina seria uma em que o corpo nunca nascesse de novo, que apodrecesse com os vermes do ano passado (GREENE, 2001, p. 87).

Em 1946, Sarah confessa aceitar Deus: "[...] devo ter aprendido a amar, pois não temia mais o deserto, já que Tu estavas lá" (GREENE, 2001, p. 90). Nessa mesma época, volta a encontrar Maurice. Almoçam juntos depois de dois anos de separação, episódio já apresentado anteriormente na narrativa, mas visto agora na perspectiva de Sarah:

[...] pensei que fosse me beijar novamente, e desejei tanto que isso acontecesse, mas um espasmo de tosse me tomou por um momento. [...] Sabia, enquanto se afastava, que estava pensando todos os tipos de inverdades que o faziam sofrer, e eu estava magoada, por ele estar sofrendo (GREENE, 2001, p. 91).

Os lances que se seguem são cenas de desejo. Sarah luta contra a sua nova crença religiosa e o desejo de estar com Maurice: “Esperaria até às 6:30, aí telefonaria para Maurice. Diria que estava indo vê-lo à noite e todas as outras noites, estou cansada de ficar sem ti" (GREENE, 2001, p. 92). Assim, planeja deixar uma carta de despedida para Henry e ir para Maurice: "Amo Maurice mais que em 1939" (Greene, 2001, p. 93). Quando termina a carta, Henry chega e, ao vê-lo, percebe: "Não posso atingi-lo [...] porque vi o que é a infelicidade" (GREENE, 2001, p. 95).

Sarah volta a viver o grande conflito: "Não tenho mais paz. Desejo-o como antes. Quero comer sanduíches com ele. Quero beber com ele num bar. Estou cansada. Quero Maurice. Quero o amor humano simples e corrupto" (GREENE, 2001, p. 99).

Maurice abandona o diário. Desesperado, telefona para Sarah, precisava vê-la, tê-la. O diário serve também como veículo de conhecimento: "Nunca soube dela antes e nunca a amei tanto. Quanto mais se sabe, mais se ama, pensei. Estava de volta ao território da confiança" (GREENE, 2001, p. 103).

Entretanto, Sarah não pode vê-lo, está muito doente. Ainda assim sai de casa, para não encontrá-lo. Maurice a segue e a encontra na igreja, sentada na nave lateral, próxima a uma 
coluna e à terrível imagem da virgem. Maurice sabia que Sarah estava com dor. Põe o braço a sua volta e toca o seu seio: “É aqui que começamos novamente. [...] Sei que fui um péssimo amante, Sarah. Foi insegurança. Não confiava em ti. Não sabia o suficiente sobre ti" (GREENE, 2001, p. 105).

Mas o conhecimento chegara tarde demais. Oito dias depois desse encontro, o telefone toca, era Henry: "Uma coisa terrível aconteceu. Você precisa saber. Sarah está morta" (GREENE, 2001, p. 109).

Um dia depois da morte de Sarah, Maurice recebe uma carta sua, na qual ela declara que, apesar de amá-lo, não pode vêlo. Conta-lhe que se tinha dirigido a um padre e que lhe dissera que queria tornar-se católica. Confessa-lhe sobre a promessa; confessa-lhe que não podia viver sem ele: "Sei que um dia te encontrarei na praça e não mais me incomodarei com Henry ou com Deus. Mas o que adianta. Acredito que existe um Deus. [...] Peço a Deus que não me mantenha viva assim" (GREENE, 2001, p. 121).

A dor é quintessencial no romance. A primeira vez que Maurice mostra certo respeito por Henry é quando o vê sofrer: "Não mais podia desprezá-lo; era um dos graduados da dor" (GREENE, 2001, p. 128). No romance, a dor é assim concebida como indispensável para uma vida plena: "[...] a felicidade nos aniquila: perdemos a nossa identidade" (2001, p. 130).

Depois da morte de Sarah, Maurice questiona sobre a matéria de que somos feitos: "Ela perdeu toda a nossa memória para sempre, é como se ao morrer tivesse roubado uma parte de mim" (GREENE, 2001, p. 123). Dessa forma, quando pensa na possibilidade de um Deus, o seu medo é só um: "Deixaria de ser Bendrix" (2001, p. 124). Reconhece-se, assim, o medo da perda do ser. Apesar de admitir que o seu registro é sobre o ódio, Maurice registra, de fato, a dúvida - o não conhecimento de si e do outro.

Sarah abandona a conviç̧ão da liberdade, da paixão, e ganha a convicção do mundo de Deus, da religiosidade, que muda o percurso de sua vida. Por último, observa-se que é a tirania das convenções que leva à tragédia. Assim, Sarah, personagem trágica da paixão, participa do mundo de forma negativa, o que inclui a negação de si mesma; o amor para ela é misterioso e contraditório, uma mistura de prazer e tortura.

Em Beyond the Pleasure Principle, Freud faz uma distinção entre o impulso libidinal, regulado pelo princípio do prazer, e os impulsos que, ao procurarem experiências desagradáveis, compulsivamente encontram suas origens em algum lugar além do princípio do prazer. Freud os denomina "impulsos de morte", reservando o termo Eros para relacionar aos impulsos da libido. Assim, enquanto Eros busca harmonizar a união, o impulso de morte produz dissonância, desintegração e fragmentação. 
Para explicar a existência dos impulsos de vida, Freud se volta para a questão da origem da sexualidade. Se, conforme o psicanalista, a origem de um impulso é "a necessidade de reconstruir um estado inicial de coisas", então nada melhor para explicar a sexualidade que o relato de Aristófanes, no Simpósio de Platão, sobre a origem do desejo sexual. Como é sabido, Aristófanes explica que originalmente havia três sexos, todos duplos (homem/homem, mulher/mulher, homem/mulher), porém um dia Zeus decidiu cortar os seres humanos em dois e, desde então, cada ser é impulsionado pela necessidade de encontrar o/a seu/a sua cara metade. "Devemos seguir a sugestão dada pelo poeta-filósofo", continua Freud, "e aventurar sobre a hipótese de que a substância viva ao tomar forma é dividida em pequenas partículas que tenta, desde então, se reunir através do instinto sexual" (1989, p. 69-70).

Percebe-se, assim, que a alusão de Freud ao mito fundador dos duplos e andrógenos na civilização europeia, no momento preciso em que discute o impulso da morte, como sugere Moi (1999, p. 436) não é nenhuma coincidência. Observa-se que, em The Uncanny, Freud relaciona a figura do duplo ao impulso de morte. O duplo "aparece em todas as formas e em todos os graus de desenvolvimento" (2000, p. 162). A partir de Otto Rank (The Double), Freud argumenta que, se cada duplo não é estranho (uncanny), é porque o duplo foi originalmente uma "segurança contra a destruição do ego [...]; e provavelmente a alma 'Imortal' foi o primeiro duplo do corpo" (2000, p. 162).

Verifica-se, dessa forma, que Maurice é o duplo da protagonista, e como tal, embora não seja à primeira vista uma figura "estranha", torna-se instrumento de morte no percurso do romance.

Apesar de ser uma narrativa que fala de paixão, é a ausência da amante que a sustenta, capacitando-a a narrativizar os interesses epistemológicos. É exatamente pela ausência que o desejo por conhecimento se torna uma busca física. Dessa forma, em relação à narrativa, a paixão e a morte ocupam posições semelhantes. Pois, se a tentativa de representar a presença da paixão ameaça encerrar a narrativa, o mesmo acontece com relação à morte. Como lembra Peter Brooks, os textos, assim como os corpos, são impulsionados pelo desejo de encontrar os seus caminhos para a morte (1984, p. 107-108).

Assinale-se que a cena crucial para a narrativa de desejo configurada em The End of the Affair é a morte. De muita importância também é distinguir entre o fim da protagonista e o epílogo do texto. A narrativa principal sugere que os encontros dos amantes dinamizam apenas a impossibilidade da união definitiva, o que conduz enfim os protagonista à ação, em vez de à resignação. Dessa forma, a morte se constitui como única opção lógica; entretanto, ao mesmo tempo, a trama conduz ao 
apagamento da possibilidade do impulso por união, e em vez disso o que se vê é a morte solitária para Sarah. Mas, como no romance oitocentista de Emily Brontë, Wuthering Heights, é morte causada pela paixão; de qualquer maneira, a amante paga pela transgressão o preço da morte.

Verifica-se assim que, se o texto apresenta como cena crucial a morte da amante, é porque essa metáfora permite que a narrativa seja vitoriosa sobre os amantes: Eros é derrotado pelo narrador. Mas é exatamente essa condição que possibilita a narratividade.

\section{Cai o pano}

Para finalizar, pode-se dizer que os romances de adultério - quer o ato sexual seja consumado, quer exista no plano do desejo apenas - são aproximáveis daquilo que um ramo da psicanálise denomina jouissance. Entretanto, aqui, o termo não poderia simplesmente significar uma experiência de gozo, alegria ou prazer. Pois esses romances falam do prazer de forma angustiada. Nesse estado de angústia, desejo e erotismo, o prazer, em suma, é tratado como o mal que é, sendo levado, nas suas formas mais sombrias, a uma experiência além do limite, transgredindo cada lei.

O romance de adultério mostra como a transgressão demarca o limite do discurso, como a experiência não pode retornar ao discurso. A transgressão positivamente consome o significado. Observa-se, então, que determinados tipos de experiência, como o adultério, revelam o desconhecido no centro da própria experiência que denota o limite da língua, do discurso, da cultura.

Como nos lembra Foucault, a transgressão carrega o limite para o limite do ser, forçando-o a encarar seu desaparecimento iminente, a encontrar-se naquilo que exclui, a experienciar a verdade positiva na própria queda. A transgressão dos amantes atravessa o limite como um flash de relâmpago na noite, dando uma intensidade densa e sombria ao que a noite nega; o flash se perde nesse espaço que marca com a sua soberania, e cala-se depois de ter nomeado o obscuro (cf. FOUCAULT, 2000, 74).

\footnotetext{
Abstract

Focused on the novel produced within the scope of literatures in English language, the present text comprehends a thematic outline which highlights the narrative representations of conjugal life. The objective of this paper is to explore marriage in a double sense: the (perfect) "marriage" between the form of the novel and the representation of fictional loves; and marriage as the novel's theme. Privileging the subtheme of adultery, as practiced
} 
by female characters, the analysis emphasizes the moments especially intense of passionate actions ("scenes", in which desire explodes in textual form that is to a certain extent detached from the total narrative that it is part of). To illustrate the theory, we propose a reading of the novel The End of the Affair, by Graham Greene.

Keywords: adultery; body; erotic desire; feminism; subjectivity

\section{REFERÊNCIAS}

BATAILLE, Georges. Literature and Evil. London: Marion Boyars, 2001.

BEAUVOIR, Simone de. The Second Sex. London: Vintage, 1997.

BROOKS, Peter. Reading for the Plot: Design and Intention in Narrative. Oxford: Clarendon Press, 1984.

CAPELLANUS, Andreas. The Art of Courtly Love. Tradução de John Jay Parry. New York: Columbia University Press, 1969.

FOUCAULT, Michel. Aesthetics, Method, and Epistemology. London: Penguin, 2000.

FREUD, Sigmund. The Uncanny. In: RIVKIN, Julie \& RYAN, Michael, ed. Literary Theory: an Anthology. Oxford: Blackwell, 2000. p. 154-167.

1989.

. Beyond the Pleasure Principle. New York: W. W. Norton,

GREENE, Graham. The End of the Affair. London: Vintage, 2001 [1951].

LEWIS, C. S. The Allegory of Love. Oxford: Oxford University Press, 1959.

MOI, Toril. What is a Woman? and Other Essays. Oxford: Oxford University Press, 1999.

OVERTON, Bill. Fictions of Female Adultery, 1684-1890. New York: Palgrave, 2002.

ROUGEMONT, Denis de. O amor e o Ocidente. Tradução de Paulo Brandi e Ethel Brandi Cachapuz. Rio de Janeiro: Guanabara, 1988. RANK, Otto. The Double. New York: Meridian, 1979.

TANNER, Tony. Adultery in the Novel. London: The John Hopkins University Press, 1979. 